\title{
Applying Blue Light Alone, or in Combination with Far-red Light, during Nighttime Increases Elongation without Compromising Yield and Quality of Indoor-grown Microgreens
}

\author{
Qinglu Ying, Yun Kong, and Youbin Zheng \\ School of Environmental Sciences, University of Guelph, 50 Stone Road East, \\ Guelph, ON N1G 2W1, Canada
}

Additional index words. arugula, biomass, chlorophyll content, far-red, leaf index, mustard, photoperiod, phytochrome, plant height

\begin{abstract}
To facilitate machine harvest for labor savings, the height of microgreens needs to reach $\approx 5 \mathrm{~cm}$. Recent studies indicate that monochromatic blue light (B) can promote stem elongation similar to far-red light (FR). To examine whether nighttime B treatments can promote plant elongation without compromising yield and quality, mustard (Brassica juncea) and arugula (Eruca sativa) microgreens were grown under different light-emitting diode (LED) lighting regimes in a growth chamber. The 16-hour daytime lighting comprised $20 \% \mathrm{~B}$ and $80 \%$ red light $(\mathrm{R})$, and had a total photosynthetic photon flux density $(P P F D)$ of $300 \mu \mathrm{mol} \cdot \mathrm{m}^{-2} \cdot \mathrm{s}^{-1}$ at canopy level. During the 8-hour nighttime, the plants were exposed to the following treatments: 1) dark (D) as one control; 2) 4 hours of $B$ at $40 \mu \mathrm{mol} \cdot \mathrm{m}^{-2} \cdot \mathrm{s}^{-1}$ followed by 4 hours of darkness (40B-D); 3 ) 4 hours of darkness followed by 4 hours of B at $40 \mu \mathrm{mol} \cdot \mathrm{m}^{-2} \cdot \mathrm{s}^{-1}$ (D-40B); 4) 8 hours of B at $20 \mu \mathrm{mol} \cdot \mathrm{m}^{-2} \cdot \mathrm{s}^{-1}$ (20B); 5$) 8$ hours of $B+F R$, and each of them at $20 \mu \mathrm{mol} \cdot \mathrm{m}^{-2} \cdot \mathrm{s}^{-1}(20 \mathrm{~B} 20 \mathrm{FR})$; and 6$) 8$ hours of $\mathrm{FR}$ at $20 \mu \mathrm{mol} \cdot \mathrm{m}^{-2} \cdot \mathrm{s}^{-1}(20 \mathrm{FR})$ as another control. The plants were harvested after 11 days of treatment. Nighttime B treatments (40B-D, D-40B, and 20B), compared with $D$, increased plant height by $34 \%$ and $18 \%$ for mustard and arugula, respectively, with no difference among the three $B$ treatments. The combination of $B$ and FR (20B20FR), compared with $B$ alone, further increased plant height by $6 \%$ and $15 \%$ for mustard and arugula, respectively, and showed a similar promotion effect as 20FR. Plant height did not meet the machine harvest requirement for both species with the $D$ treatment, but did so for mustard with the nighttime $B$ treatments and for arugula with the 20B20FR treatment. There was no difference in biomass among all treatments except that $20 \mathrm{~B}$, compared with $\mathrm{D}$, increased the fresh weight $(\mathrm{FW})$ of arugula by $12 \%$, showing a similar promotion effect as 20FR. Despite a greater promotion effect on elongation than $B$ alone, 20FR reduced the leaf index compared with D. However, B alone or the 20B20FR treatment increased leaf thickness compared with $D$, and increased chlorophyll content index (CCI), leaf index, dry matter content, and leaf thickness to varying degree with species, compared with 20FR. Overall, nighttime B alone, or its combination with FR, promoted microgreen elongation without compromising yield and quality.
\end{abstract}

Microgreens are edible seedlings harvested when their cotyledons are fully expanded, with or without the appearance of true leaves, depending on species (Treadwell

Received for publication 31 Jan. 2020. Accepted for publication 3 Apr. 2020

Published online 6 May 2020

We thank the Natural Sciences and Engineering Research Council of Canada and Greenbelt Microgreens Ltd. for their financial support. We also thank Heliospectra AB (Gothenburg, Sweden) for providing LED lighting technologies for this study. Thanks to Dave Llewellyn for his excellent technical support and informative discussion during the trials.

Y.Z. is the corresponding author. E-mail: yzheng@ uoguelph.ca.

This is an open access article distributed under the CC BY-NC-ND license (https://creativecommons. org/licenses/by-nc-nd/4.0/). et al., 2016). Of the 80 to 100 plant species currently cultivated as microgreens, the most common are from the Brassicaceae family, including mustard and arugula (Björkman et al., 2011). As specialty vegetables, microgreens have various colors and flavors, a tender texture, and a high nutritional content (Kyriacou et al., 2016; Xiao et al., 2012). The growth periods of microgreens are relatively short, as they are normally harvested within 7 to $20 \mathrm{~d}$ after sowing (Treadwell et al., 2016).

Microgreens have been increasingly produced in controlled-environment facilities with electric lighting as the sole light source, including LEDs. LED lighting has made it possible to choose specific light intensities and spectral compositions (Morrow, 2008), which can be used to regulate growth and development according to plant species (Bergstrand, 2017). LED light with a combination of $R$
$(600-700 \mathrm{~nm})$ and B (400-500 nm) (RBLED lighting) has been popularly used for horticultural production in recent years (Davis and Burns, 2016). For indoor production of microgreens, RB-LED lighting with $15 \%$ to $20 \% \mathrm{~B}$ and 300 to $400 \mu \mathrm{mol} \cdot \mathrm{m}^{-2} \cdot \mathrm{s}^{-1}$ $P P F D$ for a $16-\mathrm{h}$ photoperiod appears to be an optimal lighting regime in terms of crop yield and appearance quality (Jones-Baumgardt et al., 2019; Ying et al., 2020a). However, in the optimized lighting environment, microgreens are too short to be harvested by machine. Commercial production of microgreens is, increasingly, switching from hand- to machineharvest to reduce labor costs. Microgreens with hypocotyls less than $5 \mathrm{~cm}$ are not feasible to be harvested by machine (Canadian microgreen growers, personal communications). Also, most microgreen species are harvested with a minimum height of around $5 \mathrm{~cm}$, according to Kyriacou et al. (2016).

Although plant elongation can be promoted by creating a shade environment during daytime, there is normally a trade-off between stem elongation and plant yield under shade (Tang and Liesche, 2017). Also, our previous studies on microgreens indicated that adjusting the spectral quality of daytime lighting, such as adding small amount of FR or green light $(\mathrm{G})$ to RB-LED lighting did not change plant elongation, and even had a negative effect on the appearance quality of four microgreen species (Ying et al., 2020b). Substituting G or FR for B in RB-LED lighting, or adding FR to RB-LED lighting reduced leaf greenness or redness in lettuce and kale, and reduced relative specific chlorophyll content in lettuce and basil seedlings despite the promoted elongation responses of leaves or hypocotyls (Meng and Runkle, 2019; Meng et al., 2019). Although lowering B percentage in daytime RB-LED lighting sometimes can also promote plant height, the effects vary with species, and also can compromise other growth metrics, such as reducing leaf thickness, relative dry weight (DW), shoot FW, leaf red color, (Meng and Runkle, 2019; Nanya et al., 2012; Wollaeger and Runkle, 2015; Ying et al., 2020a), and healthpromoting phytochemical contents (our unpublished data).

To promote stem elongation without compromising other growth metrics, it may be feasible to extend the daily lighting period during nighttime (e.g., longer photoperiod). A longer photoperiod is normally associated with an increased daily light integral (DLI), which has been found to induce taller plants and greater biomass in some plant species, such as vinca (Vinca minor) and zinnia (Zinnia elegans) (Faust, 2002), and pea shoots (Pisum sativum L.) (Kong et al., 2018a). For indoor microgreen production, a $24-\mathrm{h}$ photoperiod (i.e., $0 \mathrm{~h}$ of darkness) did not cause an obvious negative effect on plant quality, and it induced a greater promotion effect on stem elongation compared with a 16-h photoperiod (Kong et al., 2019a). Nighttime lighting could be particularly useful in some regions, such as Ontario, Canada, where the price of 
electricity is much lower during the nighttime compared with the daytime. Also, the crop cycles can be potentially shortened by applying nighttime lighting, which may speed up the cash flow to some degree. However, the optimal spectral quality and lighting regimens at night for indoor-grown microgreens are unknown.

Promotion of stem elongation has been widely documented in environments containing high-level FR (Demotes-Mainard et al., 2016). The elongation response to FR is a typical shade-avoiding response mediated by phytochromes, which are photoreceptors activated mainly by $\mathrm{R}$ but deactivated by FR (Sager et al., 1988). End-of-day FR treatments were reported to enhance stem elongation in tomato (Solanum lycopersicum) (Kubota et al., 2012), chrysanthemum (Chrysanthemum morifolium) (Lund et al., 2007), and poinsettia (Euphorbia pulcherrima) (Islam et al., 2014). Nighttime FR was also extremely useful in promoting shoot elongation during the early stage for Japanese pear seedlings (Pyrus pyrifolia) (Ito et al., 2014). However, plants grown in high-level FR environments might undergo some undesirable responses, such as decreased chlorophyll content and leaf thickness (Demotes-Mainard et al., 2016). Furthermore, FR LEDs have not been popularly available for horticultural production until recent years, as a result of their higher price in the past (Kubota et al., 2012), and lower photosynthetic photon efficiency relative to $\mathrm{R}$ and $\mathrm{B}$ (Nelson and Bugbee, 2014).

Apart from FR, monochromatic B LED lighting at modest intensities (range, 40-250 $\mu \mathrm{mol} \cdot \mathrm{m}^{-2} \cdot \mathrm{s}^{-1}$ ) has been also reported to promote stem elongation in some plant species such as cherry tomato (Solanum lycopersicum L. 'Cuty') (Kim et al., 2014), cucumber (Cucumis sativus) (Hernández and Kubota, 2016), sesame (Sesamum indicum) (Hata et al., 2013), and sunflower (Helianthus annuus) (Schwend et al., 2015). Recently, based on a series of 24-h LED lighting experiments on bedding plants, microgreens, and Arabidopsis mutants, our laboratory has concluded that the promotion effect of monochromatic B is related to low phytochrome activity, which may modify the activity of $\mathrm{B}$ receptors (e.g., reduced cryptochrome activity and increased phototropin activity) (Kong and Zheng, 2020; Kong et al., 2018b, 2019b). Also, for arugula (Eruca sativa) and mustard (Brassica juncea) microgreens exposed to 24-h lighting, the promoted elongation by monochromatic B increased, with $P P F D$ decreasing from 650 to $20 \mu \mathrm{mol} \cdot \mathrm{m}^{-2} \cdot \mathrm{s}^{-1}$ (Johnson et al., 2020). However, the stem elongation promoted by 24-h lighting of modest-intensity $\mathrm{B}$ is a shade avoidance response in plants, as reduced cotyledon size and side branch number, and increased biomass partitioning to stems have been observed at the same time (Kong et al., 2018a, $2019 b$ ). It is unknown whether whole-night lighting (i.e., total $24-\mathrm{h}$ photoperiod) with a low intensity (e.g., $20-40 \mu \mathrm{mol} \cdot \mathrm{m}^{-2} \cdot \mathrm{s}^{-1}$ ) of monochromatic B can promote elongation without compromising yield and quality for indoor microgreen production with 16-h daytime RB-LED lighting.

Although both B and FR can promote stem elongation, there is not enough information comparing the promotion effect among B, FR, and B + FR. For microgreens (i.e., arugula, cabbage, and kale) exposed to 24-h lighting, B plus low-level FR slightly promoted plant elongation compared with $\mathrm{B}$, but the promotion effect was far less than that of $B$ relative to $\mathrm{R}$ (Kong et al., 2019c). It appears that $\mathrm{B}$ has a similar or greater promotion effect on microgreen elongation compared with FR, because more than one photoreceptor system (i.e., phytochromes) is involved in the promotion effect of B rather than FR (Kong and Zheng, 2020). However, in the aforementioned microgreen study, the intensity of FR was only $10 \%$ of the B intensity. A recent study indicates that, although FR alone affects plant photosynthesis minimally, it is equally efficient at driving canopy photosynthesis when it is coacting with photosynthetically active radiation (Zhen and Bugbee, 2020). Possibly, the combination of $B$ and FR at the same levels could increase plant biomass. Therefore, the promotion effects on plant elongation as well as biomass need to be compared among B, FR, and B + FR as whole-night lighting (i.e., total 24-h photoperiod) for indoor microgreen production under $16-\mathrm{h}$ daytime RB-LED lighting.

For microgreens, when the photoperiod was reduced from 24 to $16 \mathrm{~h}$, hypocotyl elongation was still promoted by monochromatic $\mathrm{B}$, and met the requirement of machine harvest (i.e., $\geq 5 \mathrm{~cm}$ ), although the promotion effect was reduced to some extent (Kong et al., 2019a). As for nighttime B treatments, it remains unclear - when the total DLI is the same-whether partial vs. whole nighttime lighting (e.g., 20- vs. 24-h photoperiod) would affect the promotion effect on elongation. Also, for partial nighttime lighting (e.g., 20-h photoperiod), when to apply B (i.e., early or late nighttime) so that it would have a greater promotion effect is unknown. It has been found that $\mathrm{B}$ reduces the promotion effect and gradually switches to an inhibitory effect on plant elongation relative to $R$ when the phytochrome photostationary state (PPS), an indicator of phytochrome activity, increases from 0.50 to 0.69 (Kong et al., 2018b, 2019c). Apparently, the activity of cryptochrome, B photoreceptor, is increased by activated phytochrome, possibly resulting from a crosstalk between the two photoreceptor systems (Liu et al., 2016). A previous study of cucumber (Cucumis sativus L.) seedlings indicated that phytochrome still remained activated after "lights off" and might last for several hours in the dark, although the phytochrome activity gradually decreased over time (Gaba and Black, 1979). Consequently, the effect of nighttime $\mathrm{B}$ on plant elongation may differ between early and later hours during the nighttime as a result of the difference in phytochrome activity. This speculation needs to be confirmed for indoor microgreen production with 16-h daytime RB-LED lighting.

Although many previous studies have reported the promotion effect of B as the sole light source on plant elongation, little information is available on the application of $B$ as a supplemental lighting source to indoor microgreen production. Therefore, the objective of this study was 1) to evaluate the effect of nighttime $\mathrm{B}$, or its combination with FR treatments, relative to dark and FR, on hypocotyl elongation as well as crop yield and appearance quality; and 2) with equal DLI, to determine the optimum nighttime lighting strategy (e.g., initiation time and duration) using $\mathrm{B}$ for indoor microgreen production with 16-h RB-LED lighting during the daytime.

\section{Materials and Methods}

Plant materials and growing conditions. This experiment was performed in a walk-in growth chamber $(7.3 \times 4.0 \times 2.5 \mathrm{~m})$, which was divided into six compartments by opaque curtains, from Oct. to Nov. 2018. Seeds of arugula (Eruca sativa; 'unknown name', Suba Seeds Company S.P.A., Longiano, FC, Italy) and mustard (Brassica juncea; 'mizuna', Johnny's Selected Seeds, Winslow, ME) were sown in fiber trays $(48.5 \times$ $23 \times 3.5 \mathrm{~cm})$ were filled with substrate consisting of $30 \%$ compost, $30 \%$ peat, $30 \%$ coir, and $10 \%$ perlite $(\mathrm{v} / \mathrm{v})$. The seeding rate was $36 \mathrm{~g} \cdot \mathrm{m}^{-2}$ for both arugula and mustard, and each tray had one species. After seeding, the sown trays were placed on a bench in each compartment for lighting treatments. The substrate was prepared by Greenbelt Microgreens Ltd. (Lynden, Ontario, Canada), and had a $\mathrm{pH}$ of 6.9 and an electrical conductivity (EC) of $1.9 \mathrm{dS} \cdot \mathrm{m}^{-1}$. The nutrient content (in milligrams per kilogram) in the substrate was measured by a commercial analytical laboratory (A\&L Canada Laboratories Inc., London, Ontario, Canada) using test methods for composting and compost, and the result was as follows: N, 9400; P, 329; $\mathrm{K}, 1410 ; \mathrm{S}, 220 ; \mathrm{Mg}, 295 ; \mathrm{Ca}, 1390 ; \mathrm{Zn}$, 9.4; $\mathrm{Mn}, 10 ; \mathrm{Fe}, 47 ; \mathrm{Cu}, 0.6 ; \mathrm{Na}, 218$; and $\mathrm{B}, 0.7 \mathrm{mg} \cdot \mathrm{kg}^{-1}$. All trays were top irrigated at least daily using well water $(\mathrm{pH}=7.5$, $\mathrm{EC}=0.8 \mathrm{dS} \cdot \mathrm{m}^{-1}$ ) until drainage was visible. The temperature was set at $20{ }^{\circ} \mathrm{C}$ during the daytime (10:00 AM-2:00 AM) and $17{ }^{\circ} \mathrm{C}$ during the nighttime, and the relative humidity (RH) was set at $70 \%$. Temperature and $\mathrm{RH}$ were controlled by an environmental control system (Titan, Argus Controls Systems Ltd., Surrey, British Columbia, Canada).

Experimental design and treatments. The experiment was a randomized complete block design with six treatments and three consecutive replicates. The six treatments differed only during the 8-h nighttime, but had the same 16-h daytime lighting, which was provided by RB-LED with a photon flux ratio of $20 \% \mathrm{~B}$ and $80 \% \mathrm{R}$ at a $P P F D$ of $300 \mu \mathrm{mol} \cdot \mathrm{m}^{-2} \cdot \mathrm{s}^{-1}$ from 10:00 AM to 2:00 AM. 
The six nighttime treatments were: 1) D, dark for $8 \mathrm{~h}$ as one control; 2) 40B-D, 40 $\mu \mathrm{mol} \cdot \mathrm{m}^{-2} \cdot \mathrm{s}^{-1} \mathrm{~B}$ for the first $4 \mathrm{~h}$ and dark for last $4 \mathrm{~h}$; 3) D-40B, dark for the first $4 \mathrm{~h}$ and $40 \mu \mathrm{mol} \cdot \mathrm{m}^{-2} \cdot \mathrm{s}^{-1} \mathrm{~B}$ for last $4 \mathrm{~h}$; 4) $20 \mathrm{~B}, 20$ $\mu \mathrm{mol} \cdot \mathrm{m}^{-2} \cdot \mathrm{s}^{-1} \mathrm{~B}$ for $8 \mathrm{~h}$; 5) 20B20FR: 20 $\mu \mathrm{mol} \cdot \mathrm{m}^{-2} \cdot \mathrm{s}^{-1} \quad \mathrm{~B}$ and $20 \mu \mathrm{mol} \cdot \mathrm{m}^{-2} \cdot \mathrm{s}^{-1} \mathrm{FR}$ together for $8 \mathrm{~h}$; and 6) 20FR: $20 \mu \mathrm{mol} \cdot \mathrm{m}^{-2} \cdot \mathrm{s}^{-1}$ $\mathrm{FR}$ for $8 \mathrm{~h}$ as another control. Both daytime and nighttime light treatments were provided solely by LEDs (LX602C; Heliospectra AB, Gothenburg, Sweden). For each replicate, the six treatments were allocated randomly to the six compartments in the growth chamber, and there were two trays of microgreens (one species per tray) for each treatment. The trial was replicated three times over time, and the treatment locations were randomized within the growth chamber for each replication.

In each compartment, two LED lamps were hung $56.5 \mathrm{~cm}$ above the top of the substrate (measured from the bottom of the lamps) and separated by $36 \mathrm{~cm}$ (on center). The individual $\mathrm{B}$ and $\mathrm{R}$ channels were set to achieve an average $P P F D$ of $300 \mu \mathrm{mol} \cdot \mathrm{m}^{-2} \cdot \mathrm{s}^{-1}$ during the 16-h daytime. In addition, the $B$ and FR channels were set up to provide the various nighttime spectrum treatments, all of which had an average photon flux density of 20 or 40 $\mu \mathrm{mol} \cdot \mathrm{m}^{-2} \cdot \mathrm{s}^{-1}$. The actual lighting conditions are summarized in Table 1. The PPS values for the daytime lighting and the different nighttime lighting were calculated using the protocol (Mah et al., 2019) developed by our laboratory according to Sager et al. (1988). The DLI and daily photon integral were calculated using the total photons from 400 to $700 \mathrm{~nm}$ and 400 to $800 \mathrm{~nm}$, respectively. Photon flux density and spectra of the LED arrays were controlled by using software (System Assistant Version 1.3.0; Heliospectra, $\mathrm{AB})$. Photon flux density and spectra were measured at 16 spots (a $4 \times 4$ grid) within a square treatment area of $0.25 \mathrm{~m}^{2}$, centered between the LED fixtures, using a radiometrically calibrated spectrometer (Flame-S; Ocean Optics, Inc., Dunedin, FL) with a $25-\mu \mathrm{m}$ slit, coupled to a $1.89 \mathrm{~m} \times 400 \mu \mathrm{m}$ fiber optic patch chord with a CC-3 cosine corrector. Light intensity and spectra were also checked at the end of each replicate.
Data collection and analyses. Both arugula and mustard microgreens were harvested $11 \mathrm{~d}$ after seeding. Plants were harvested with two fully expanded cotyledons and visual observation of the firstemerged true leaves. For each replicate and each species, three subsamples (with a substrate surface area of $76.4 \mathrm{~cm}^{2}$ each, including plants and the substrate) of microgreens were sampled randomly from each tray using a cylindrical core sampler. All the microgreens in each subsample were then cut at substrate level and measured for $\mathrm{FW}$. These plants were then dried at $65{ }^{\circ} \mathrm{C}$ until a constant weight was reached to determine DW. Twenty-five plants from each genotype were selected randomly from the remainder of the microgreens in each tray to evaluate plant height. Another 15 plants $(5$ plants $\times 3$ sets) were selected randomly from the plants left in each tray, and were separated into cotyledons and hypocotyls for quality evaluation. After measuring FW of cotyledons and stems separately, they were imaged using a flat-bed digital scanner (Canoscan LiDE 25; Canon Inc., Tokyo, Japan). The images were saved in JPG format with 600-dpi resolution, and they were later processed using ImageJ 1.42 software (National Institutes of Health, Bethesda, MD) to determine cotyledon area. After scanning, the cotyledons and hypocotyls were dried separately at $65{ }^{\circ} \mathrm{C}$ until a constant weight and DW were recorded. The leaf index, dry matter content, and specific leaf area (SLA) were determined for the three sets of five plants from each replicate and each treatment, and were calculated as

$$
\text { Leaf index }(\mathrm{g} \cdot \mathrm{g}-1)=
$$

DW of cotyledons/DW of hypocotyls

Dry matter content $(\%)=\mathrm{DW} / \mathrm{FW} \times 100 \quad$ [2]

$$
\begin{gathered}
\operatorname{SLA}\left(\mathrm{cm}^{2} \cdot \mathrm{g}^{-1}\right) \\
=\text { Cotyledon area } / \mathrm{DW} \text { of cotyledons }
\end{gathered}
$$

Another 15 plants from each tray were selected randomly to measure the CCI of the cotyledons using a chlorophyll meter (SPAD 502; Spectrum Technologies, Inc., Aurora, IL).

Data were subjected to analysis of variance using SPSS software (version 25.0; IBM, Anorak, NY) followed by multiple comparisons using Tukey's honestly significant difference test at $P \leq 0.05$. Data are presented as mean \pm SE $(n=3)$.

\section{Results}

Compared with D, all nighttime B treatments increased plant height, with similar trends in both microgreen species (Fig. 1). The average plant heights for the nighttime $B$ treatments (i.e., 40B-D, D-40B, and 20B) were $6.4 \mathrm{~cm}$ and $4.2 \mathrm{~cm}$ for mustard and arugula, respectively. The three nighttime $\mathrm{B}$ treatments showed a similar promotion effect on plant height in both species, and increased plant height by $34 \%$ for mustard (Fig. 1A) and $18 \%$ for arugula (Fig. 1B) compared with $\mathrm{D}$. The combination of $\mathrm{B}$ and FR treatment (20B20FR), compared with B alone further increased plant height by $6 \%$ and $15 \%$ for mustard and arugula, respectively, and showed a similar promotion effect as 20FR. The plant height for the 20B20FR treatment was $6.8 \mathrm{~cm}$ and $5.1 \mathrm{~cm}$ for mustard and arugula, respectively.

The FW of mustard was unaffected by any of the nighttime treatments (Fig. 2A). The FW of arugula was $12 \%$ greater for both the 20B and 20FR treatments compared with $\mathrm{D}$, with $20 \mathrm{~B}$ showing a similar promotion effect as 20FR (Fig. 2B). There were no treatment effects on DW for mustard or arugula (Fig. 2C and D).

Cotyledon area of arugula was increased by $21 \%$ with the D- $40 \mathrm{~B}$ treatment compared with $\mathrm{D}$, whereas other treatments had no effect on this trait in either species (Table 2). Leaf indices were greater in mustard for the D, D-40B, and 20B20FR treatments than for $20 \mathrm{FR}$, and in arugula for $20 \mathrm{~B}$ and $20 \mathrm{~B} 20 \mathrm{FR}$ than for $\mathrm{D}$. The dry matter content was less with the 20FR treatments compared with all other treatments for mustard, but was not different among all the treatments for arugula. The CCI of the cotyledons was increased by $12 \%, 13 \%$, and $10 \%$ for the D- $40 \mathrm{~B}, 20 \mathrm{~B}$, and

Table 1. Photon flux density (PFD) from blue $(400-500 \mathrm{~nm})$ and red $(600-700 \mathrm{~nm})$ light, photosynthetically active radiation $(P A R)$, and phytochrome

\begin{tabular}{|c|c|c|c|c|c|c|c|c|c|}
\hline \multirow[b]{2}{*}{ Nighttime treatment } & \multicolumn{4}{|c|}{ Daytime PFD $\left(\mu \mathrm{mol} \cdot \mathrm{m}^{-2} \cdot \mathrm{s}^{-1}\right)^{\mathrm{z}}$ and PPS } & \multicolumn{3}{|c|}{ Nighttime PFD $\left(\mu \mathrm{mol} \cdot \mathrm{m}^{-2} \cdot \mathrm{s}^{-1}\right)$ and PPS } & \multirow[b]{2}{*}{$\operatorname{DPI}^{\mathrm{y}}\left(\mathrm{mol} \cdot \mathrm{m}^{-2} \cdot \mathrm{d}^{-1}\right)$} & \multirow[b]{2}{*}{ DLI $\left(\mathrm{mol} \cdot \mathrm{m}^{-2} \cdot \mathrm{d}^{-1}\right)$} \\
\hline & Blue & Red & $P A R^{\mathrm{y}}$ & PPS & Blue & Far-red & PPS & & \\
\hline$\overline{\mathrm{D}^{\mathrm{x}}}$ & $60 \pm 0.5$ & $239 \pm 2.1$ & $299 \pm 2.6$ & $0.88 \pm 0.0$ & - & - & - & 17.3 & 17.3 \\
\hline 40B-D & $60 \pm 0.5$ & $239 \pm 1.3$ & $299 \pm 1.4$ & $0.88 \pm 0.0$ & $40 \pm 0.3$ & - & $0.53 \pm 0.0$ & 17.9 & 17.9 \\
\hline $20 \mathrm{~B}$ & $60 \pm 0.8$ & $237 \pm 0.4$ & $298 \pm 1.3$ & $0.88 \pm 0.0$ & $20 \pm 0.4$ & - & $0.52 \pm 0.0$ & 17.9 & 17.9 \\
\hline 20B20FR & $61 \pm 0.7$ & $238 \pm 1.1$ & $300 \pm 2.2$ & $0.88 \pm 0.0$ & $20 \pm 0.5$ & $20.3 \pm 0.5$ & $0.23 \pm 0.0$ & 18.5 & 17.9 \\
\hline $20 \mathrm{FR}$ & $61 \pm 0.9$ & $239 \pm 2.5$ & $300 \pm 1.9$ & $0.88 \pm 0.0$ & - & $19.7 \pm 0.4$ & $0.18 \pm 0.0$ & 17.9 & 17.3 \\
\hline
\end{tabular}
photostationary state (PPS) during daytime; average PFD from blue and far-red (700-800 nm) light, and PPS during nighttime; and the daily photon integral (DPI) and daily light integral (DLI) under six light spectral treatments.

${ }^{\mathrm{z}}$ Data are means \pm SE $(\mathrm{n}=3)$.

${ }^{\mathrm{y}} \mathrm{PPS}=$ phytochrome photostationary state, which is the estimated phytochrome photoequilibrium according to the method by Sager et al. (1988). $P A R=$ photosynthetically active radiation ranging from 400 to $700 \mathrm{~nm}$. DPI $=$ daily photon integral $\left(\mathrm{mol}^{-2} \cdot \mathrm{m}^{-2} \cdot \mathrm{d}^{-1}\right)$, ranging from 400 to $800 \mathrm{~nm}$.

${ }^{\mathrm{x}} \mathrm{D}=$ dark for $8 \mathrm{~h} ; 40 \mathrm{~B}-\mathrm{D}=40 \mu \mathrm{mol} \cdot \mathrm{m}^{-2} \cdot \mathrm{s}^{-1}$ blue light for the first $4 \mathrm{~h}$ and dark for last $4 \mathrm{~h} ; \mathrm{D}-40 \mathrm{~B}=$ dark for the first $4 \mathrm{~h}$ and $40 \mu \mathrm{mol} \cdot \mathrm{m}^{-2} \cdot \mathrm{s}^{-1} \mathrm{blue}$ light for the last 4 $\mathrm{h} ; 20 \mathrm{~B}=20 \mu \mathrm{mol} \cdot \mathrm{m}^{-2} \cdot \mathrm{s}^{-1}$ blue light for $8 \mathrm{~h} ; 20 \mathrm{~B} 20 \mathrm{FR}=20 \mu \mathrm{mol} \cdot \mathrm{m}^{-2} \cdot \mathrm{s}^{-1}$ blue light and $20 \mu \mathrm{mol} \cdot \mathrm{m}^{-2} \cdot \mathrm{s}^{-1}$ far-red light together for $8 \mathrm{~h} ; 20 \mathrm{FR}=20 \mu \mathrm{mol} \cdot \mathrm{m}^{-2} \cdot \mathrm{s}^{-1}$ far red light for $8 \mathrm{~h}$. The six nighttime treatments had the same 16 -h daytime lighting, which was provided by a combination of $20 \%$ blue and $80 \%$ red light-emitting diodes at a photosynthetic photon flux density of $300 \mu \mathrm{mol} \cdot \mathrm{m}^{-2} \cdot \mathrm{s}^{-1}$ from 10:00 AM to 2:00 AM. 


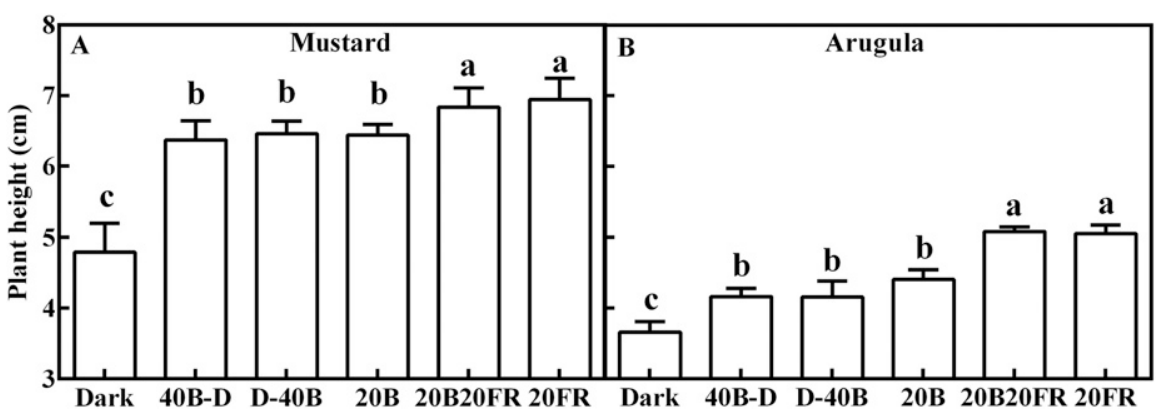

Fig. 1. Effect of nighttime spectrum treatments on height of mustard (A) and arugula (B) microgreens. Data are means \pm SE $(n=3)$. Bars bearing the same letter are not significantly different by Tukey's honestly significant difference test at $P \leq 0.05$. D, dark for $8 \mathrm{~h} ; 40 \mathrm{~B}-\mathrm{D}, 40 \mu \mathrm{mol} \cdot \mathrm{m}^{-2} \cdot \mathrm{s}^{-1}$ blue light for the first $4 \mathrm{~h}$ and dark for last $4 \mathrm{~h}$; D-40B, dark for the first $4 \mathrm{~h}$ and $40 \mu \mathrm{mol} \cdot \mathrm{m}^{-2} \cdot \mathrm{s}^{-1}$ blue light for the last $4 \mathrm{~h} ; 20 \mathrm{~B}, 20$ $\mu \mathrm{mol} \cdot \mathrm{m}^{-2} \cdot \mathrm{s}^{-1}$ blue light for $8 \mathrm{~h} ; 20 \mathrm{~B} 20 \mathrm{FR}, 20 \mu \mathrm{mol} \cdot \mathrm{m}^{-2} \cdot \mathrm{s}^{-1}$ blue light and $20 \mu \mathrm{mol} \cdot \mathrm{m}^{-2} \cdot \mathrm{s}^{-1}$ far-red light together for $8 \mathrm{~h} ; 20 \mathrm{FR}, 20 \mu \mathrm{mol} \cdot \mathrm{m}^{-2} \cdot \mathrm{s}^{-1}$ far-red light for $8 \mathrm{~h}$. The six nighttime treatments had the same 16-h daytime lighting, which was provided by a combination of $20 \%$ blue and $80 \%$ red light-emitting diodes at a photosynthetic photon flux density of $300 \mu \mathrm{mol} \cdot \mathrm{m}^{-2} \cdot \mathrm{s}^{-1}$ from 10:00 AM to 2:00 AM.

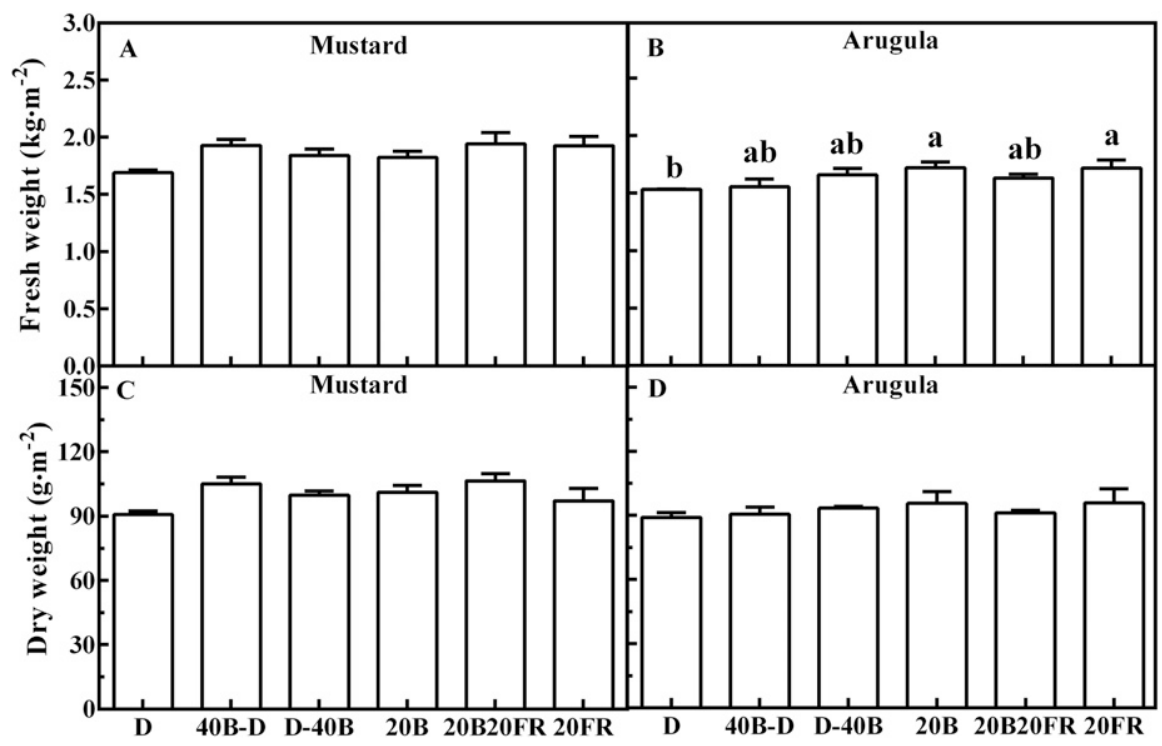

Fig. 2. Effect of nighttime spectrum treatments on fresh weight $(\mathbf{A}, \mathbf{B})$ and dry weight $(\mathbf{C}, \mathbf{D})$ of mustard and arugula microgreens. Data are means $\pm S E(n=3)$. Bars bearing the same letter are not significantly different by Tukey's honestly significant difference test at $P \leq 0.05$. D, dark for 8 h; 40B-D, $40 \mu \mathrm{mol} \cdot \mathrm{m}^{-2} \cdot \mathrm{s}^{-1}$ blue light for the first $4 \mathrm{~h}$ and dark for last $4 \mathrm{~h}$; D-40B, dark for the first $4 \mathrm{~h}$ and $40 \mu \mathrm{mol} \cdot \mathrm{m}^{-2} \cdot \mathrm{s}^{-1}$ blue light for the last $4 \mathrm{~h} ; 20 \mathrm{~B}, 20 \mu \mathrm{mol} \cdot \mathrm{m}^{-2} \cdot \mathrm{s}^{-1}$ blue light for $8 \mathrm{~h} ; 20 \mathrm{~B} 20 \mathrm{FR}$, $20 \mu \mathrm{mol} \cdot \mathrm{m}^{-2} \cdot \mathrm{s}^{-1}$ blue light and $20 \mu \mathrm{mol} \cdot \mathrm{m}^{-2} \cdot \mathrm{s}^{-1}$ far-red light together for $8 \mathrm{~h} ; 20 \mathrm{FR}, 20 \mu \mathrm{mol} \cdot \mathrm{m}^{-2} \cdot \mathrm{s}^{-1}$ far-red light for $8 \mathrm{~h}$. The six nighttime treatments had the same 16-h daytime lighting, which was provided by a combination of $20 \%$ blue and $80 \%$ red light-emitting diodes at a photosynthetic photon flux density of $300 \mu \mathrm{mol} \cdot \mathrm{m}^{-2} \cdot \mathrm{s}^{-1}$ from 10:00 AM to 2:00 $\mathrm{AM}$.

20B20FR treatments, respectively, for mustard, and by $9 \%$ for the 20B20FR treatment for arugula compared with $20 \mathrm{FR}$. The SLA of arugula decreased by $17 \%$ with the D-40B, 20B, and 20B20FR treatments compared with D, and by $15 \%$ with the $20 \mathrm{~B} 20 \mathrm{FR}$ treatment compared with 20FR, but this trait showed no difference in all treatments for mustard.

\section{Discussion}

Nighttime B increases elongation growth, with a promotion effect comparable to $F R$, for indoor microgreen production. Compared with $\mathrm{D}$ (i.e., no lighting at night), nighttime $\mathrm{B}$ treatments (i.e., 40B-D, D-40B, and 20B) promoted elongation by $34 \%$ and $18 \%$ for mustard and arugula, respectively, in our study. Apparently, the extended lighting time contributed to elongation growth. Normally, stem elongation increased by extended lighting time could be caused by increased photoassimilation for growth, and/or the production of light-dependent elongation-promoting hormones (Bergstrand, 2017; Warrington and Norton, 1991; Yamaguchi, 2008). In our study, there was a lesser possibility of increased assimilation supply by nighttime lighting with $\mathrm{B}$, which was also supported by a similar dry biomass for nighttime B treatments and darkness. During the relatively short growth period (from seeding to cotyledon fully unfolding), it seems that microgreens mainly experience a transition from heterotrophic to autotrophic growth, and photosynthesis contributes little to elongation growth (Jones-Baumgardt et al., 2019). In a previous study on petunias, high levels of bioactive gibberellins were found under $\mathrm{B}$, which was related to $\mathrm{B}$ enhanced elongation growth (Fukuda et al., 2016). Therefore, gibberellin production could have been increased by the extended lighting with monochromatic B at night for the tested microgreen species in our study, although this needs further confirmation.

The promotion effect of nighttime $\mathrm{B}$ on elongation growth was comparable to FR in our study. Under nighttime B vs. FR treatments, the microgreen plants were only $8 \%$ and $17 \%$ shorter for mustard and arugula, respectively. Also, the plant height of mustard under nighttime $\mathrm{B}$ treatments reached the greater than $5-\mathrm{cm}$ requirement for machine harvest, suggesting that nighttime B can be potentially used to promote plant elongation for microgreen production. Recent studies in our laboratory have found that the promoted elongation growth by B is related to low phytochrome activity, indicated by a lower PPS value (Kong et al., 2018b, 2019c). The PPS threshold value to induce activated phytochrome responses is controversial, but a PPS value of more than 0.6 could generally induce these responses (Stutte, 2009). In our study, the PPS values were less than 0.6, indicating a potentially deactivated phytochrome response for all nighttime $\mathrm{B}$ and $\mathrm{FR}$ treatments. However, B treatments had a relatively greater PPS value than FR $(0.52$ vs. 0.18), which may explain the slightly reduced promotion effect on elongation.

Nighttime B vs. FR is better for indoor microgreen production in terms of yield and quality. In our study, $20 \mu \mathrm{mol} \cdot \mathrm{m}^{-2} \cdot \mathrm{s}^{-1} \mathrm{~B}$ applied throughout the nighttime for $8 \mathrm{~h}$ increased microgreen $\mathrm{FW}$ by $12 \%$ for arugula compared with $\mathrm{D}$, showing a biomass promotion effect similar to FR. Similarly, FW of Chinese kale (Brassica alboglabra 'Bailey') was increased by $41 \%$ when 50 or $100 \mu \mathrm{mol} \cdot \mathrm{m}^{-2} \cdot \mathrm{s}^{-1}$ of B was supplemented for $12 \mathrm{~h}$ in a greenhouse (Li et al., 2019). The increased FW of arugula under 20B would potentially promote yield and benefit production, because microgreens are sold on an FW basis. Furthermore, B (as opposed to FR) has been more popular for a long time because of the lower price of the LED lighting fixture, and its greater photosynthetic photon efficiency (Kubota et al., 2012; Nelson and Bugbee, 2014). However, in recent years the price of FR LED has decreased rapidly, so the comparison of economic effects between the two types of LED lighting needs further study.

Extended lighting using B alone at night also increased microgreen quality compared with D or FR in many cases. For example, cotyledon area and thickness (i.e., reciprocal of SLA) were increased for arugula with B treatments compared with $\mathrm{D}$, dry matter content and CCI were increased for mustard, and leaf index was enhanced for both species with B alone compared with FR. These quality improvements under nighttime $\mathrm{B}$ treatments would potentially benefit microgreen production, because larger and greener cotyledons are more appealing in appearance to most customers. Also, a greater dry matter content and thicker leaves can potentially increase microgreen shelf life, because 
Table 2. Effect of nighttime spectrum treatments on cotyledon area, leaf index, dry matter content, chlorophyll content index (CCI), and specific leaf area (SLA) of arugula and mustard microgreens.

\begin{tabular}{|c|c|c|c|c|c|}
\hline Nighttime treatment & Cotyledon area $\left(\mathrm{cm}^{2} /\right.$ plant $)$ & Leaf index $\left(\mathrm{g} \cdot \mathrm{g}^{-1}\right)$ & Dry matter content $(\%)$ & $\mathrm{CCI}$ & SLA $\left(\mathrm{cm}^{2} \cdot \mathrm{g}^{-1}\right)$ \\
\hline \multicolumn{6}{|l|}{ Mustard } \\
\hline 40B-D & $2.5 \pm 0.1$ & $2.3 \pm 0.5 \mathrm{ab}$ & $5.5 \pm 0.1 \mathrm{a}$ & $32.6 \pm 0.6 \mathrm{ab}$ & $74.3 \pm 7.5$ \\
\hline D-40B & $2.3 \pm 0.1$ & $2.3 \pm 0.6 \mathrm{a}$ & $5.4 \pm 0.1 \mathrm{a}$ & $34.5 \pm 0.6 \mathrm{a}$ & $77.5 \pm 1.7$ \\
\hline 20B20FR & $2.5 \pm 0.2$ & $2.4 \pm 0.6 \mathrm{a}$ & $5.5 \pm 0.1 \mathrm{a}$ & $33.9 \pm 0.6 \mathrm{a}$ & $68.8 \pm 4.7$ \\
\hline $20 \mathrm{FR}$ & $2.3 \pm 0.2$ & $1.8 \pm 0.2 \mathrm{~b}$ & $5.1 \pm 0.2 b$ & $30.9 \pm 0.3 b$ & $77.6 \pm 3.1$ \\
\hline \multicolumn{6}{|l|}{ Arugula } \\
\hline D-40B & $3.1 \pm 0.3 \mathrm{a}$ & $2.8 \pm 0.4 \mathrm{ab}$ & $5.7 \pm 0.2$ & $34.1 \pm 1.1 \mathrm{ab}$ & $61.7 \pm 3.9 \mathrm{bc}$ \\
\hline $20 \mathrm{~B}$ & $2.8 \pm 0.2 \mathrm{ab}$ & $2.2 \pm 0.1 \mathrm{bc}$ & $5.7 \pm 0.1$ & $35.0 \pm 0.0 \mathrm{ab}$ & $59.3 \pm 3.5 \mathrm{bc}$ \\
\hline 20B20FR & $2.9 \pm 0.2 \mathrm{ab}$ & $2.2 \pm 0.3 \mathrm{bc}$ & $5.8 \pm 0.1$ & $35.3 \pm 0.3 \mathrm{a}$ & $55.4 \pm 2.6 \mathrm{c}$ \\
\hline $20 \mathrm{FR}$ & $2.8 \pm 0.2 \mathrm{ab}$ & $1.9 \pm 0.0 \mathrm{c}$ & $5.7 \pm 0.2$ & $32.5 \pm 0.3 \mathrm{~b}$ & $65.3 \pm 7.5 \mathrm{ab}$ \\
\hline
\end{tabular}

${ }^{\mathrm{z}}$ Leaf index $\left(\mathrm{g} \cdot \mathrm{g}^{-1}\right)=$ dry weight of cotyledons $\div$ dry weight of hypocotyls.

${ }^{\mathrm{y}} \mathrm{D}=$ dark for $8 \mathrm{~h} ; 40 \mathrm{~B}-\mathrm{D}=40 \mu \mathrm{mol} \cdot \mathrm{m}^{-2} \cdot \mathrm{s}^{-1}$ blue light for the first $4 \mathrm{~h}$ and dark for last $4 \mathrm{~h} ; \mathrm{D}-40 \mathrm{~B}=$ dark for the first $4 \mathrm{~h}$ and $40 \mu \mathrm{mol} \cdot \mathrm{m}^{-2} \cdot \mathrm{s}^{-1} \mathrm{blue} \mathrm{light} \mathrm{for} \mathrm{the} \mathrm{last} 4$ $\mathrm{h} ; 20 \mathrm{~B}=20 \mu \mathrm{mol} \cdot \mathrm{m}^{-2} \cdot \mathrm{s}^{-1}$ blue light for $8 \mathrm{~h} ; 20 \mathrm{~B} 20 \mathrm{FR}=20 \mu \mathrm{mol} \cdot \mathrm{m}^{-2} \cdot \mathrm{s}^{-1}$ blue light and $20 \mu \mathrm{mol} \cdot \mathrm{m}^{-2} \cdot \mathrm{s}^{-1}$ far-red light together for $8 \mathrm{~h} ; 20 \mathrm{FR}=20 \mu \mathrm{mol} \cdot \mathrm{m}^{-2} \cdot \mathrm{s}^{-1} \mathrm{far}-$ red light for $8 \mathrm{~h}$. The six nighttime treatments had the same 16-h daytime lighting, which was provided by a combination of $20 \%$ blue and $80 \%$ red light-emitting diodes at a photosynthetic photon flux density of $300 \mu \mathrm{mol} \cdot \mathrm{m}^{-2} \cdot \mathrm{s}^{-1}$ from 10:00 AM to 2:00 AM.

${ }^{\mathrm{x}}$ Data are means $\pm \mathrm{SE}(\mathrm{n}=3)$. Letters are shown only when there is significant treatment effect at $P \leq 0.05$. Means sharing the same letter are not significantly different by Tukey's honestly significant difference test at $P \leq 0.05$.

microgreens are highly perishable products (Di Gioia et al., 2015). Taking into account the negative effects of FR on some quality traits, monochromatic B appears to be a better nighttime spectrum treatment for increasing plant height of indoor-grown microgreens.

Strategies of using nighttime $B$ for indoor microgreen production. In our study, the shorter time $(4 \mathrm{~h})$ of $\mathrm{B}$ treatments (D-40B and 40B-D) during the nighttime did not affect microgreen stem elongation, yield, or quality compared with a longer 8-h B treatment (20B). This differed from a recent study in our laboratory, where shortening the daily lighting time from $24 \mathrm{~h}$ to $16 \mathrm{~h}$ reduced the promotion effects of monochromatic $\mathrm{B}$ on stem elongation, cotyledon size, and plant color in microgreens to some degree (Kong et al., 2019a). Also, in natural light conditions in the greenhouse, the shortened photoperiod inhibited plant elongation in some species through reduced DLI (Bergstrand, 2017). In our study, although the duration of nighttime B treatment was shortened from $8 \mathrm{~h}$ to $4 \mathrm{~h}$, the total DLI did not change because a twofold light intensity (40 vs. $20 \mu \mathrm{mol} \cdot \mathrm{m}^{-2}$ $\cdot \mathrm{s}^{-1}$ ) was used for 4-h B lighting. However, in previous studies, the shortened photoperiods were also accompanied by lower DLIs. This may explain in part the inconsistency between the results of our study and those of others.

For partial nighttime lighting (4 $\mathrm{h}$ rather than $8 \mathrm{~h}$ ), B treatments at earlier vs. later night hours (40B-D vs. D-40B) had similar effects on microgreen elongation, yield, and quality in our study. The sole-source RBLEDs used for daytime lighting in our study should induce a relatively high phytochrome activity (PPS $=0.88$; Table 1 ) immediately after the light is turned off. However, monochromatic B may need some time to reduce the PPS. For white mustard (Sinapsis alba) seedlings, around $30 \mathrm{~min}$ was needed for monochromatic $\mathrm{B}$ to reduce the PPS value to initiate inactive phytochrome responses
(Jabben et al., 1982). Possibly, at the beginning (e.g., $30 \mathrm{~min}$ ) of the 4-h nighttime B treatments, plant elongation was inhibited to a larger degree with the 40B-D treatment compared with $\mathrm{D}-40 \mathrm{~B}$ as a result of the gradually decreasing phytochrome activity at night. However, this greater inhibition at the beginning with the 40B-D vs. the D-40B treatment might be eliminated by the elongation promoted by later 4-h dark with the 40B-D treatment. The underlying mechanism still needs further study. Nevertheless, the flexible time window to apply B during the nighttime provides an opportunity to lower lighting costs, because the price of electricity is much less during the off-peak period in some regions.

The combination of $\mathrm{B}$ and FR further promoted plant elongation compared with $\mathrm{B}$ alone. and showed a promotion effect similar to FR, but exerted no additive effect on yield or other quality metrics. Similarly, after adding low-level (10\% total PPFD) FR to B, plant height increased slightly in arugula and mustard microgreens under 24-h sole-source LED lighting compared with B (Kong et al., 2019c). The increases in plant height under $B+$ $\mathrm{FR}$, compared with $\mathrm{B}$, may have resulted from further reduced phytochrome activity, as indicated by a lower PPS value ( 0.23 vs. 0.52 ). However, the sensitivity of the elongation response to the decreased phytochrome activity seems to vary among species. In our study, the plants grown under monochromatic $B$ alone treatments met the $5-\mathrm{cm}$ height requirement for machine harvest for mustard, but not for arugula. For arugula, only B together with FR could promote elongation sufficient to meet the height requirement. It appears that, for indoor microgreen production, B alone-or together with FR - can be used as nighttime lighting for promoting elongation, depending on plant species sensitivity to decreased phytochrome activity.

In summary, for indoor production of mustard and arugula microgreens under 16-h day- time RB-LED lighting, 40B-D, D-40B, and 20B increased plant height for both species compared with $\mathrm{D}$, and had no differences among the three B treatments. 20B20FR further increased plant height for both species compared with $\mathrm{B}$ alone, and showed a promotion effect similar to 20FR. 20B vs. D increased FW for arugula, showing a similar promotion effect as 20FR. Compared with D, B alone or 20B20FR increased leaf thickness, but 20FR reduced the leaf index. Furthermore, B alone or 20B20FR, compared with 20FR, increased the CCI, leaf index, dry matter content, and leaf thickness to varying degrees with species. Apparently, although $20 \mathrm{FR}$, compared with B alone, had a greater promotion effect on elongation, it showed some negative effects on microgreen quality. Plant height met the machine harvest requirement for mustard under nighttime B treatments and for arugula under 20B20FR, but not for both species under D. Overall, there is the potential to use monochromatic $\mathrm{B}$ with or without FR, depending on plant species, during the nighttime to promote stem elongation without compromising crop yield quality appearance.

\section{Literature Cited}

Bergstrand, K.J.I. 2017. Methods for growth regulation of greenhouse produced ornamental pot and bedding plants: A current review. Folia Hort. 29:63-74.

Björkman, M., I. Klingen, A.N.E. Birch, A.M. Bones, T.J.A. Bruce, T.J. Johansen, R. Meadow, J. Mølmann, R. Seljåsen, L.E. Smart, and D. Stewart. 2011. Phytochemicals of Brassicaceae in plant protection and human health: Influences of climate, environment and agronomic practice. Phytochemistry 72:538-556.

Davis, P.A. and C. Burns. 2016. Photobiology in protected horticulture. Food Energy Secur. 5:223-238.

Demotes-Mainard, S., T. Péron, A. Corot, J. Bertheloot, J. Le Gourrierec, S. Pelleschi-Travier, L. Crespel, P. Morel, L. Huché-Thélier, R. Boumaza, A. Vian, V. Guérin, N. Leduc, and S. 1Sakr. 2016. Plant responses to red and far- 
red lights: Applications in horticulture. Environ. Expt. Bot. 121:4-21.

Di Gioia, F., C. Mininni, and P. Santamaria. 2015. How to grow microgreens, p. 51-81. In: F. Di Gioia and P. Santamaria (eds.). Microgreens: Novel fresh and functional food to explore all the value of biodiversity. ECO-logica srl., Bari, Italy.

Faust, J.E. 2002. First research report. Light management in greenhouses: II. Plant growth responses to daily light integrals. <http:// www.specmeters.com/assets/1/7/A051.pdf \$.

Fukuda, N., C. Ajima, T. Yukawa, and J.E. Olsen. 2016. Antagonistic action of blue and red light on shoot elongation in petunia depends on gibberellin, but the effects on flowering are not generally linked to gibberellin. Environ. Expt. Bot. 121:102-111.

Gaba, V. and M. Black. 1979. Two separate photoreceptors control hypocotyl growth in green seedlings. Nature 278:51-54.

Hata, N., Y. Hayashi, E. Ono, H. Satake, A. Kobayashi, T. Muranaka, and A. Okazawa. 2013. Differences in plant growth and leaf sesamin content of the lignan-rich sesame variety "Gomazou" under continuous light of different wavelengths. Plant Biotechnol. 30:1-8.

Hernández, R. and C. Kubota. 2016. Physiological responses of cucumber seedlings under different blue and red photon flux ratios using LEDs. Environ. Expt. Bot. 121:66-74.

Islam, M.A., D. Tarkowská, J.L. Clarke, D.R. Blystad, H.R. Gislerød, S. Torre, and J.E. Olsen. 2014. Impact of end-of-day red and far-red light on plant morphology and hormone physiology of poinsettia. Scientia Hort. 174:77-86.

Ito, A., T. Saito, T. Nishijima, and T. Moriguchi. 2014. Effect of extending the photoperiod with low-intensity red or far-red light on the timing of shoot elongation and flower-bud formation of 1-year-old Japanese pear (Pyrus pyrifolia). Tree Physiol. 34:534-546.

Jabben, M., C. Beggs, and E. Schaufer. 1982. Dependence of $\mathrm{Pfr} /$ Ptot-ratios on light quality and light quantity. Photochem. Photobiol. 35: 709-712.

Johnson, R.E., Y. Kong, and Y. Zheng. 2020. Elongation growth mediated by blue light varies with light intensities and plant species: A comparison with red light in arugula and mustard seedlings. Environ. Expt. Bot. 169: 103898.

Jones-Baumgardt, C., D. Llewellyn, Q. Ying, and Y. Zheng. 2019. Intensity of sole-source lightemitting diodes affects growth, yield, and quality of Brassicaceae microgreens. HortScience 54:1168-1174.

Kim, E.Y., S.A. Park, B.J. Park, Y. Lee, and M.M. Oh. 2014. Growth and antioxidant phenolic compounds in cherry tomato seedlings grown under monochromatic light-emitting diodes. Hort. Environ. Biotechnol. 55:506-513.

Kong, Y., D. Kamath, and Y. Zheng. 2019a. Blue versus red light can promote elongation growth independent of photoperiod: A study in four Brassica microgreens species. HortScience 54:1955-1961.

Kong, Y., D. Llewellyn, and Y. Zheng. 2018a. Response of growth, yield, and quality of pea shoots to supplemental light-emitting diode lighting during winter greenhouse production. Can. J. Plant Sci. 740:732-740.

Kong, Y., K. Schiestel, and Y. Zheng. 2019b. Pure blue light effects on growth and morphology are slightly changed by adding low-level UVA or far-red light: A comparison with red light in four microgreen species. Environ. Expt. Bot. 157:58-68.

Kong, Y., K. Schiestel, and Y. Zheng. 2019c. Maximum elongation promoted as a shadeavoidance response by blue light is related to deactivated phytochrome: A comparison with red light in four microgreen species Can. J. Plant Sci. 2019, doi: 10.1139/CJPS2019-0082.

Kong, Y., M. Stasiak, M.A. Dixon, and Y. Zheng. 2018 b. Blue light associated with low phytochrome activity can promote elongation growth as shade-avoidance response: A comparison with red light in four bedding plant species. Environ. Expt. Bot. 155:345-359.

Kong, Y. and Y. Zheng. 2020. Phototropin is partly involved in blue-light-mediated stem elongation, flower initiation, and leaf expansion: A comparison of phenotypic responses between wild Arabidopsis and its phototropin mutants. Environ. Expt. Bot. 171:103967.

Kubota, C., P. Chia, Z. Yang, and Q. Li. 2012. Applications of far-red light emitting diodes in plant production under controlled environments. Acta Hort. 952:59-66.

Kyriacou, M.C., Y. Rouphael, F. Di, A. Kyratzis, F. Serio, M. Renna, S. De Pascale, and P. Santamaria. 2016. Micro-scale vegetable production and the rise of microgreens. Trends Food Sci. Technol. 57:103-115.

Li, Y., Y. Zheng, H. Liu, Y. Zhang, Y. Hao, S. Song, and B. Lei. 2019. Effect of supplemental blue light intensity on the growth and quality of Chinese kale. Hort. Environ. Biotechnol. 60: 49-57.

Liu, B., Z. Yang, A. Gomez, B. Liu, C. Lin, and Y. Oka. 2016. Signaling mechanisms of plant cryptochromes in Arabidopsis thaliana. J. Plant Res. 129:137-148.

Lund, J.B., T.J. Blom, and J.M. Aaslyng. 2007. Endof-day lighting with different red/far-red ratios using light-emitting diodes affects plant growth of Chrysanthemum xmorifolium Ramat. 'Coral Charm'. HortScience 42:1609-1611.

Mah, J.J., D. Llewellyn, and Y. Zheng. 2019. Protocol for converting spectrometer radiometric data to photon flux units. Guelph, University of Guelph. < http://www.ces.uoguelph.ca/ TechNotes.shtml $>$.

Meng, Q., N. Kelly, and E.S. Runkle. 2019. Substituting green or far-red radiation for blue radiation induces shade avoidance and promotes growth in lettuce and kale. Environ. Expt. Bot. 162:383-391.
Meng, Q. and E.S. Runkle. 2019. Far-red radiation interacts with relative and absolute blue and red photon flux densities to regulate growth, morphology, and pigmentation of lettuce and basil seedlings. Scientia Hort. 255:269-280.

Morrow, R.C. 2008. LED lighting in horticulture. HortScience 43:1947-1950.

Nanya, K., Y. Ishigami, S. Hikosaka, and E. Goto. 2012. Effects of blue and red light on stem elongation and flowering of tomato seedlings. Acta Hort. 956:261-266.

Nelson, J.A. and B. Bugbee. 2014. Economic analysis of greenhouse lighting: Light emitting diodes vs. high intensity discharge fixtures. PLoS One 9:E99010.

Sager, J.C., W.O. Smith, J.L. Edwards, and K.L. Cyr. 1988. Photosynthetic efficiency and phytochrome photoequilibria determination using spectral data. Trans. ASAE 31:1882-1889.

Schwend, T., D. Prucker, and H. Mempel. 2015. Red light promotes compact growth of sunflowers. Eur. J. Hort. Sci. 80:56-61.

Stutte, G.W. 2009. Light-emitting diodes for manipulating the phytochrome apparatus. HortScience 44:231-234.

Tang, Y. and J. Liesche. 2017. The molecular mechanism of shade avoidance in crops: How data from Arabidopsis can help to identify targets for increasing yield and biomass production. J. Integr. Agr. 16:1244-1255.

Treadwell, D.D., R. Hochmuth, L. Landrum, and W. Laughlin. 2016. Microgreens: A new specialty crop. Univ. Florida IFAS Ext. Bull. HS1164. <https://edis.ifas.ufl.edu/hs1164>.

Warrington, I.J. and R.A. Norton. 1991. An evaluation of plant growth and development under various daily quantum integrals. J. Amer. Soc. Hort. Sci. 116:544-551.

Wollaeger, H.M. and E.S. Runkle. 2015. Growth and acclimation of impatiens, salvia, petunia, and tomato seedlings to blue and red light. HortScience 50:522-529.

Xiao, Z., G.E. Lester, Y. Luo, and Q. Wang. 2012. Assessment of vitamin and carotenoid concentrations of emerging food products: Edible microgreens. J. Agr. Food Chem. 60:7644-7651.

Yamaguchi, S. 2008. Gibberellin metabolism and its regulation. Annu. Rev. Plant Biol. 59:225-251.

Ying, Q., Y. Kong, C. Jones-Baumgardt, and Y. Zheng. 2020a. Responses of yield and appearance quality of four Brassicaceae microgreens to varied blue light proportion in red and blue light-emitting diodes lighting. Scientia Hort. 259:1168-1174.

Ying, Q., Y. Kong, and Y. Zheng. 2020b. Growth and appearance quality of four microgreen species under light-emitting diode lights with different spectral combinations. HortScience (in press)

Zhen, S. and B. Bugbee. 2020. Far-red photons have equivalent efficiency to traditional photosynthetic photons: Implications for redefining photosynthetically active radiation. Plant Cell Environ. 1-14, doi: 10.1111/pce.13730. 